Microaggressions in Historical Context 1

Microaggressions as part of the historical context of stigma and prejudice Michael W. Kraus

\author{
Jun Won Park
}

Yale University, School of Management 


\begin{abstract}
In this comment we articulate one central weakness in Lilienfeld's (2017) perspective on microaggression research in psychological science: Namely, that any analysis of modern forms of expressed prejudice, be they subtle or overt, that does not acknowledge the historical context in which these forms of prejudice are expressed is likely to be fraught with challenges and potential for misunderstanding. Here we articulate how this ahistorical context of prejudice has a prominent history in psychological science, and has frequently led otherwise well-meaning and rigorous research studies to incomplete conclusions about the prejudice experienced by historically marginalized groups. We then discuss how this ahistorical perspective on expressed prejudice leads to misconceptions about microaggression research. Ultimately, the Lilienfeld (2017) piece is a compelling case for considering, whenever possible, the perspectives of those for whom the surrounding historical context of prejudice is most salient. This need is particularly great with respect to research questions that examine the experience of prejudice and thereby directly rely on the wisdom of individuals who come from traditionally marginalized groups and thus are personally steeped in the history, traditions, and thought perspectives that arise from those conditions. (188 words)
\end{abstract}




\section{Microaggressions as part of the historical context of stigma and prejudice}

When undergraduate psychology majors first come in contact with social psychological studies of prejudice it is often with respect to an experimental study of a faux facial scar (Kleck \& Strenta, 1980). In the study, researchers use makeup to apply a visible scar to the faces of female participants before, ostensibly with moisturizer, the scar is removed for these participants without their knowledge. Following this manipulation, participants interact with a confederate who is unaware of the manipulation. In comparison to participants who did not receive this facial scar application and removal, participants who believe the scar still appears on their face perceived more prejudice on the part of the confederate (Kleck \& Strenta, 1980). In textbooks the study is often used to highlight the possibility that prejudice is sometimes only in the minds of those who experience it. The actual experience of prejudice, however, is never this simple: Visible markers of stigma and prejudice are not so easily removed as make-up. Moreover, people who experience prejudice can actually verify its existence through examining past and current legislation (e.g., Jim Crow, anti-miscegenation laws, redlining, travel bans) and anecdotal evidence (e.g., uttered racial slurs, refusal of service at a store), and have the capacity to develop coping strategies in response (e.g., Miller \& Kaiser, 2001). In this fashion, a well-designed experiment aimed at uncovering the causal levers that elicit experiences of prejudice among the marginalized misses an important feature of prejudice and the focus of this commentary—its broader historical context (for a review, see Richeson \& Sommers, 2016).

Here we argue that the Lilienfeld (2017) piece on microaggressions research is another example of a well-written and rigorous analysis that nevertheless mischaracterizes the experiences of prejudice for historically marginalized populations. Critically, the piece fails because it does not consider experiences of prejudice, be they subtly expressed microaggressions 
or other overt acts of discrimination, in the historical context within which they are situated. Specifically, we will argue that removing historical context (1) downplays the target's point of view in understanding the experience of microaggressions, and (2) ignores the significant social and economic status dynamics at play in perceiving and experiencing subtle forms of prejudice like microaggressions. Overall, we contend that the lack of access and inclusion of marginalized groups in psychological science might be the main underlying factor slowing the development of the microaggression research paradigm: Psychological science does not appropriately value the perspectives of individuals who are steeped in the historical context of prejudice and are uniquely suited to add insights to the study of microaggressions and other subtle forms of prejudice.

\section{The Historical Context of Prejudice}

As experimental social psychologists in practice (or in training), we tend to examine aspects of the experiences of people broken into specific units of analysis: In the case of an individual's decision to help another person, we might examine the situational factors that influenced the action (Darley \& Batson, 1973), the cognitions that co-occur with the decision to help (Rand, Greene, \& Nowak, 2012), the feelings and motivations that also arise from it (Goetz, Keltner, \& Simon-Thomas, 2010), and the individual differences that predispose an individual to help more or less across contexts (Piff, Kraus, Côté, Cheng, \& Keltner, 2010; Korndorfer, Egloff, \& Schmikle, 2015). But, as most of our colleagues will attest, an analysis of behavior is incomplete without also including the cultural and historical context in which that behavior arises. This position is an important foundation for theory and research in several subsections of psychological science (Henrich, Heine, \& Norenzayan, 2010; Markus \& Kitayama, 1991), in medicine (Bronfenbrenner, 1977), and in sociology (e.g., Fanon, 1963/2007). We contend, as 
others have argued before us (Richeson \& Sommers, 2016), that the historical context is crucially relevant in the study, and critique, of theory and research on the concept of prejudice.

A historical examination of prejudice with respect to ethnic minority populations in the United States suggests that expressed prejudice is reflective of dominant societal norms, which change over time (Crandall, Eshleman, \& O’Brien, 2002; Pettigrew, 1991). Whereas in the past, laws promoting slavery and segregation were the norm, those laws have largely fallen out of favor in the present and been replaced by subtler, but no less pernicious, forms of prejudice: a prison system that disproportionally punishes ethnic minorities; redlining that segregates neighborhoods with preferential lending practices for Whites; breakdowns in maintenance and oversight of public infrastructure that occur exclusively in cities populated by ethnic minority groups (e.g., Flint, Michigan, which is still battling dangerous levels of lead in the water supply). Norms in the realm of expressed prejudice have also shifted, reducing overt and public violence against ethnic minorities (e.g., lynchings and other public displays of violence) in favor of subtler forms of bias wherein individuals are motivated to not appear prejudiced in front of others (Crandall et al., 2002; Devine, 1989). The concept of microaggressions - defined as subtle slights, insults, or snubs directed toward marginalized groups (Sue et al., 2007)—follows naturally in this historical perspective because it is consistent with our understanding of contemporary forms of prejudice.

But subtlety does not necessarily mean that the treatment of marginalized groups has significantly improved, certainly not across all outcomes. With respect to economic outcomes, for instance, economic differences between White and Black Americans have not improved: The median income of a Black family was $51.1 \%$ of the median for White families in 1947, and has only increased to $57.3 \%$ by 2013 , despite expressions of prejudice being much subtler now than 
in the past (Economic Policy Institute, 2016). Even when educational attainment is controlled for, college-educated Black Americans earn $80.96 \%$ of what is earned by college-educated Whites, and this gap in 2015 is slightly worse than what it was in 1973 (86.5\%; Economic Policy Institute, 2016). Disparities in health and life expectancy show similar trends (e.g., Umberson et al., 2017). Despite the increased politeness and subtlety of expressions of prejudice, many historical social and economic inequalities between racial minority groups have remained stable over the years.

Social theorists reason that subtle expressions of prejudice are far more effective in maintaining hierarchical differences between groups than are overt law-based forms because it is natural to question the very existence of the prejudice itself when expressed with subtlety (e.g., Salvatore \& Shelton, 2007). Subtle expression allows prejudice to exist as a visible, yet hard to verify, aspect of social life that maintains current unequal social and economic conditions between majority and minority group members (c.f., Foucault, 1977/2010). It is within this historical context that microaggressions enter. These subtle expressions of prejudice can theoretically contribute to the maintenance of economic and social inequalities between majority and minority individuals in society while simultaneously raising the specter of doubt in their very existence.

The historical context suggests that though they are thought to be less severe, modern forms of prejudice appear to be doing the same job as more overt forms of the past by disadvantaging individuals based on their membership in ethnic minority groups and other marginalized populations in society in favor of dominant group members. The primary danger of an ahistorical account of microaggressions is that it too easily misleads people into believing that 
the existence of subtle prejudice is up for debate, thereby occluding an examination of the impact, scope, and function of microaggressions before it can begin.

\section{Microaggressions from the Target's Point of View}

Our historical analysis suggests that psychological science can make the most progress by understanding microaggressions from a place of historical knowledge. In particular, this perspective highlights the importance of understanding microaggressions from the target's point of view.

Lilienfeld (2017) questions whether microaggressions can be validly assessed by selfreports of people who experience them. We contend that targets of prejudice have the requisite historical knowledge to best evaluate the behavior of others as expressions of subtle prejudice. In fact, we contend that the face validity of microaggressions as expressions of prejudice is only made clear when understood within their historical context. Several examples are illustrative of the importance of understanding historical context in interpreting another's behavior as a form of subtle prejudice or not. For instance, a seemingly benign question posed toward an Asian American student like "What is your nationality?" highlights the subordinate citizenship status that ethnic minorities hold relative to Whites - a citizenship status that Japanese Americans had directly questioned when they were placed in internment camps during World War II while their Italian and German American counterparts continued to live in their homes. When a person says something as well-intentioned as "Everyone can succeed in this society, if they work hard enough," to an American Indian student, it is possible that the student will interpret that statement in the historical context within which their relatives were systematically eradicated from North America so that Whites could settle on the land (the statement is also false according to economic mobility data; Economic Policy Institute, 2016). In this fashion, the fairly benign 
articulation of beliefs in meritocracy becomes decidedly hostile when it is considered fully within the surrounding historical context. As another example, the assertion that "When I look at you, I don't see color" suggests that people are able to step outside of the historical context of race relations in America, and that a person's race and culture can be separated from how they experience the world (for a review of studies examining the negative impacts of colorblind ideologies, see Rattan \& Ambady, 2013).

These examples highlight the critical importance of historical knowledge — which is particularly high among targets of prejudice — in evaluating the behavior of others as evidence of prejudice or not. At best, these exemplars of microaggression show that the expresser has an alarming lack of insight into the history of prejudice against marginalized populations in America. This blissful ignorance suggests a fundamental lack of empathy for, or understanding of, the experiences of individuals from marginalized groups. At worst, microaggressions are a willful denial and erasure of the past and current prejudice experienced by marginalized populations, or a tacit agreement that the pain and injustice inflicted, or being inflicted, disproportionately upon marginalized populations in America is fair, just, and deserved.

We also question Lilienfeld's (2017) assertion that expressers of microaggressions can be accurate perceivers of the prejudice (or not) in their own behavior. For example, research on prejudice and discrimination suggests that it is normative in recent decades for individuals to be unwilling to express or admit to prejudice (e.g., Crandall et al., 2002; Devine, 1989), casting doubt on the willingness of expressers to honestly report whether their own behavior was an expression of prejudice (e.g., Bonilla-Silva, 2010). In another example, though White participants self-reported enjoying an interaction with a racial minority, the same participants showed physiological responses characterized by decreased cardiac output and increased vaso- 
constriction - a pattern of physiological reactions consistent with a feeling of threat during the cross-race encounter (Mendes et al., 2007). These findings indicate that expressers of prejudice may be unable to report their experiences regarding prejudice in cross-race interactions with accuracy, limiting the validity of perceivers' conclusions about the presence of microaggressions.

Research on the cognitive costs of prejudice shows a similar pattern with respect to casual observations of others' prejudice: In that research, White and Black students were exposed to a hiring manager who exhibited no bias, ambiguous bias, or blatant bias in hiring a student of another racial group, before having their executive functioning assessed via Stroop task (Salvatore \& Shelton, 2007). Whereas Black students, performed worse on the Stroop task when exposed to ambiguous bias relative to blatant bias or no bias-presumably because the uncertainty of ambiguous bias expended cognitive resources - White students performed worse cognitively during blatant bias, but equally well during exposure to ambiguous bias or no bias (Salvatore \& Shelton, 2007). In essence, unlike Black students who appeared to grapple with the potential bias in the ambiguous condition, White students responded in a way that suggests they did not differentiate between no bias and subtle or ambiguous bias (c.f., Murphy, Richeson, Shelton, Rheinschmidt, \& Bergsieker, 2013).

We would also like to add that approaching microaggressions research from the subjective perspective of the target is not a controversial approach in other realms of psychological science, and in fact, may elicit greater predictive validity. For instance, self-rated health predicts mortality better than do physiological examinations or expert assessments of health (e.g., Idler \& Benyamini, 1997). As well, subjective assessments of loneliness predict mortality better than do objective assessments of social relationships (e.g., Luo, Hawkley, Waite, 
\& Cacioppo, 2012). The reasoning for these outcomes is similar in some ways to why we value the target's perspective in research on microaggressions: Individuals have the best vantage point from which to understand their own subjective experiences and histories. This is not to say that mono-source bias is not a limitation in research using common methods as Lilienfeld (2017) writes. However, applying insights from research on self-rated health and loneliness, we expect target self-reports of microaggressions to be high in predictive validity.

\section{Microaggressions Affirm Social and Economic Hierarchies}

One feature of our historical analysis is that it highlights the role of social and economic status in the experience and interpretation of microaggressions. Research on social status in the social and economic sciences suggests consistently that high status individuals are motivated to maintain their elevated positions in society (Brandt, 2013; Kraus \& Callaghan, 2014; Kraus \& Keltner, 2013; Weber, 1930/2002). In one example of this phenomenon, White, male, and wealthier members of the US House of Representatives were more likely to sponsor legislation that maintained economic inequality in society than were their non-White, female, and less wealthy colleagues (Kraus \& Callaghan, 2014). In related research, White participants reminded that Whites were quickly becoming a minority ethnic group tended to show stronger support for political policies that close American borders relative to Whites not provided this demographic information (e.g., building a wall on the Mexico border, making English the US official language; Craig \& Richeson, 2014a; 2014b).

Several studies also indicate that high status individuals (e.g., high social class, whites) tend to believe that society is fairer and more merit-based than their low status counterparts (Kraus \& Keltner, 2013; Knowles \& Lowery, 2012; Lowery et al., 2006). These motives to see society as merit-based contribute to objective errors in perceiving the historical context of status 
hierarchies. For example, White participants who experienced a threat denied their own historical privilege more than White participants not under threat (Phillips \& Lowery, 2015). Taken together, these studies suggest that elevated status motivates status maintenance behavior, especially during moments when that status is being challenged.

Microaggressions can be understood as serving as an elusive and effective way for dominant group members to maintain their favored social and economic standing relative to marginalized groups. And because microaggressions are subtle forms of expressed prejudice that can have many negative consequences, high status members of society can use microaggressions to maintain economic and social inequalities across many domains while simultaneously suggesting that such behaviors are unintended (e.g., Bonilla-Silva, 2010). Moreover, understanding the potential hierarchy maintenance function of microaggressions once again highlights the importance of the target's point of view in the study of subtle prejudiceexpressers of prejudice may be motivated to strategically or inadvertently question the existence of prejudice.

Lilienfeld (2017) laments the increasing concern on college and university campuses about microaggressions because of the early developmental stage of the construct and because the concern places excess burden on teachers. While we acknowledge that research on micraggressions is at early stages, our historical analysis suggests a slightly different interpretation of this increasing concern: That university campuses would generate backlash against concern about microaggressions fits our status maintenance explanation — opportunity for advancement combined with a call from students from marginalized populations for greater care and sensitivity in discussions is a challenge to the status hierarchy that is explicit at colleges and universities. In essence, faculty and administration accustomed to choosing what to teach might 
be frustrated with the increased control of content that students are insisting upon in their courses. Thus, objections to the concept of microaggressions may be motivated in part by a desire to maintain control of student learning. In line with our historical perspective, similar faculty and administration resistance at colleges and universities has been observed in the past when students sought increased control of university spaces (e.g., Kitchell, Griffin, Selver, \& Most, 1990).

\section{Psychological Science Needs Greater Diversity}

We share Lilienfeld's (2017) perspective that greater diversity is a hallmark of a healthy scientific enterprise, and in particular a healthy psychological science. We contend that psychological science would benefit from an infusion of researchers from marginalized backgrounds, as these researchers would have unique insight into and experiences with subtle forms of prejudice (Du Bois, 1942). Indeed this is much of what Sue and colleagues (2007) argue drives their descriptive work of microaggressions in focus groups and qualitative settings: A desire to better understand the experience of subtle prejudice from the point of view of people who have experienced it. Counter to Lilienfeld (2017) and others (Duarte et al., 2015), we contend that ideological diversity would not add much to our understanding of prejudice given prior research indicating that political conservatives are more likely to see society as fairer than it actually is (Jost et al., 2003), to commit estimation errors in perceptions of economic inequality (Davidai \& Gilovich, 2015), and to exhibit motivated denial of prejudice (Lowery et al., 2007).

Taking a broad perspective, we see the Lilienfeld (2017) piece as a reflection of some research in psychological science wherein the study of prejudice is undertaken without full consideration of its historical context. As an example, Lilienfeld (2017, p. 161) suggests that, aside from microassaults which can be considered blatant prejudice, microaggressions should 
instead be called "inadvertent racial slights," to reflect the "unintentional nature of most or virtually all microaggressions." Our historical analysis makes us extremely wary of such a renaming: Focusing on the intention behind microaggressions detracts from the critical point that prejudice need not be intentional to have detrimental effects on targets: Throughout history, behaviors that are now widely thought of as clear acts of prejudice were described in the past using other plausible reasons unrelated to prejudice. To illustrate, in the US Supreme Court decision of Plessy vs. Ferguson (1896) that upheld separate but equal state institutions, segregation was described as a natural preference to avoid unwanted "commingling of the two races" (p. 163) rather than as an expression of prejudice. A focus of microaggression research on the intentions of expressers obscures the broader historical context of prejudice and its continued social and economic impacts on the marginalized, and could potentially lead to wrong empirical conclusions. After all, awareness does not change the fact that expressers still incur privileged status as a result of expressed prejudice.

We argue that psychological science is particularly susceptible to these kinds of conclusions about subtle prejudice given its lack of diversity. Most societies do not publish data on the demographic characteristics of their members, but data are available from the Society of Personality and Social Psychology (SPSP, 2015). SPSP has many members that study intergroup processes related to prejudice, and the data reflect a startling lack of diversity among full members in terms sexual orientation, disability, and race/ethnicity (see Figure 1).

Figure 1. Sexual orientation, disability status, and race/ethnicity data for full members of the Society for Personality and Social Psychology. Data are reproduced from: http://ow.ly/d/4uk9 


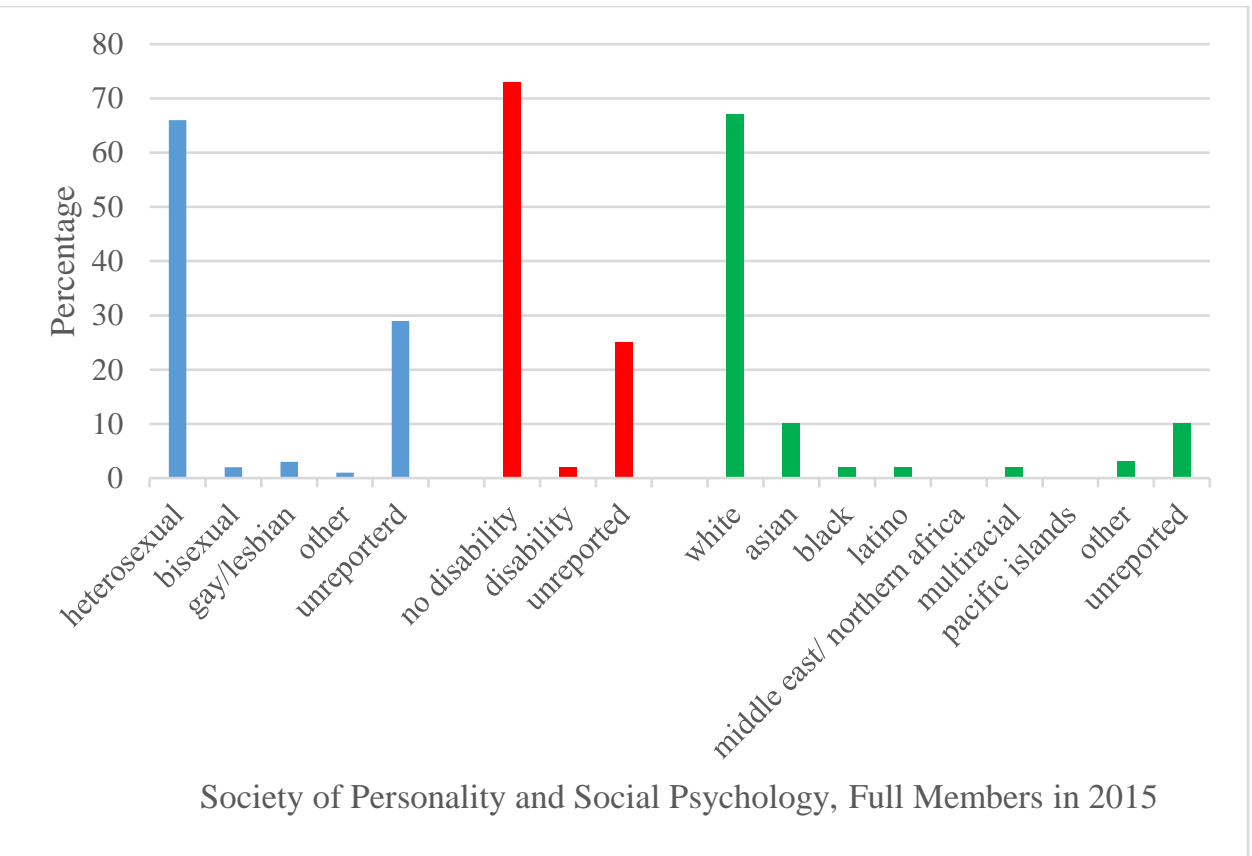

It is our hypothesis that a lack of access and inclusion for marginalized populations reduces the collective knowledge of the history of prejudice available to psychological science. This deficiency in knowledge plays out in a lower number of researchers who conduct studies of subtle prejudice, review those studies for journals, conferences, and granting agencies, and ultimately provide critical analyses of those literatures. Until representation, access, and inclusion of marginalized groups increases, progress in our study and understanding of subtle prejudice might be incremental. In fact, we agree with Sue (1999) that missteps in the study and analysis of subtle prejudice are more a reflection of an ongoing lack of support for diversity in our scientific discipline than of improper approaches to research. For these reasons, we contend that it is critical for researchers who study prejudice in all of its forms to keep historical context in mind, and to consider whenever possible the perspectives of those for whom this context is most salient. 
Overall, the Lilienfeld (2017) paper makes several constructive recommendations for improving the microaggression research program in the future that involve longitudinal designs, avoiding common method variance, creating sharper theoretical boundaries for the concept in question, and exploring new empirical approaches. These are actually quite astute recommendations for any research paradigm like that of microaggressions, with less than a decade of theoretical and empirical development. We would like to add that in our own reading of this literature on subtle prejudice, we wonder if the prefix "micro" should be applied to subtle forms of prejudice with such a widespread and effective capacity to maintain existing economic and social inequalities. 


\section{References}

Bonilla-Silva, E. (2010). Racism without racists: Color-blind racism and the persistence of racial inequality in the United States. Rowman \& Littlefield.

Brandt, M. J. (2013). Do the disadvantaged legitimize the social system? A large-scale test of the status-legitimacy hypothesis. Journal of personality and social psychology, 104(5), 765.

Bronfenbrenner, U. (1977). Toward an experimental ecology of human development. American Psychologist, 32(7), 513-531.

Crandall, C. S., Eshleman, A., \& O'brien, L. (2002). Social norms and the expression and suppression of prejudice: the struggle for internalization. Journal of personality and social psychology, 82(3), 359.

Craig, M. A., \& Richeson, J. A. (2014). More diverse yet less tolerant? How the increasingly diverse racial landscape affects white Americans' racial attitudes. Personality and Social Psychology Bulletin, 750-761.

Craig, M. A., \& Richeson, J. A. (2014). On the precipice of a "majority-minority" America: Perceived status threat from the racial demographic shift affects White Americans' political ideology. Psychological Science, 25(6), 1189-1197.

Darley, J. M., \& Batson, C. D. (1973). " From Jerusalem to Jericho": A study of situational and dispositional variables in helping behavior. Journal of Personality and Social Psychology, 27(1), 100-108.

Davidai, S., \& Gilovich, T. (2015). Building a more mobile America: One income quintile at a time. Perspectives on Psychological Science, 10(1), 60-71.

Devine, P. G. (1989). Stereotypes and prejudice: Their automatic and controlled components. Journal of Personality and Social Psychology, 56(1), 5-18. 
Du Bois, W. E. B. (1942). Review of Robert Warner's New Haven Negroes: A Social History, in American Historical Review, January, 47: 376-377.

Economic Policy Institute, State of Working America Data Library, "Wages,” 2016.

Fanon, F. (1963/2007). The wretched of the earth. Grove/Atlantic.

Foucault, M. (1977/2012). Discipline \& punish: The birth of the prison. Vintage.

Goetz, J. L., Keltner, D., \& Simon-Thomas, E. (2010). Compassion: An evolutionary analysis and empirical review. Psychological Bulletin, 136(3), 351-374.

Henrich, J., Heine, S. J., \& Norenzayan, A. (2010). Beyond WEIRD: Towards a broad-based behavioral science. Behavioral and Brain Sciences, 33(2-3), 111-135.

Idler, E. L., \& Benyamini, Y. (1997). Self-rated health and mortality: a review of twenty-seven community studies. Journal of health and social behavior, 21-37.

Jost, J. T., Glaser, J., Kruglanski, A. W., \& Sulloway, F. J. (2003). Political conservatism as motivated social cognition. Psychological Bulletin, 129(3), 339-375.

Kitchell, M., Griffin, S., Selver, V., \& Most, S. (1990). Berkeley in the Sixties (Vol. 117). Los Angeles: Kitchell Films.

Kleck, R. E., \& Strenta, A. (1980). Perceptions of the impact of negatively valued physical characteristics on social interaction. Journal of Personality and Social Psychology, 39(5), 861-873.

Knowles, E. D., \& Lowery, B. S. (2012). Meritocracy, self-concerns, and Whites' denial of racial inequity. Self and Identity, 11(2), 202-222.

Kraus, M. W., \& Callaghan, B. (2014). Noblesse oblige? Social status and economic inequality maintenance among politicians. PloS ONE, 9(1), e85293. 
Kraus, M. W., \& Keltner, D. (2013). Social class rank, essentialism, and punitive judgment. Journal of Personality and Social Psychology, 105(2), 247-261.

Kraus, M. W., \& Tan, J. J. (2015). Americans overestimate social class mobility. Journal of Experimental Social Psychology, 58, 101-111.

Lilienfeld, S. O. (2017). Microaggressions: Strong claims, inadequate evidence. Perspectives on Psychological Science, 12(1), 138-169.

Lowery, B. S., Knowles, E. D., \& Unzueta, M. M. (2007). Framing inequity safely: The motivated denial of White privilege. Personality and Social Psychology Bulletin, 33, 1237-1250.

Lowery, B. S., Unzueta, M. M., Knowles, E. D., \& Goff, P. A. (2006). Concern for the ingroup and opposition to affirmative action. Journal of Personality and Social Psychology, 90, 961-974.

Luo, Y., Hawkley, L. C., Waite, L. J., \& Cacioppo, J. T. (2012). Loneliness, health, and mortality in old age: A national longitudinal study. Social science \& medicine, 74(6), 907-914.

Markus, H. R., \& Kitayama, S. (1991). Culture and the self: Implications for cognition, emotion, and motivation. Psychological Review, 98(2), 224-253.

Mendes, W. B., Blascovich, J., Hunter, S. B., Lickel, B., \& Jost, J. T. (2007). Threatened by the unexpected: Physiological responses during social interactions with expectancy-violating partners. Journal of Personality and Social Psychology, 92(4), 698-716.

Mendoza-Denton, R., Downey, G., Purdie, V. J., Davis, A., \& Pietrzak, J. (2002). Sensitivity to status-based rejection: implications for African American students' college experience. Journal of personality and social psychology, 83(4), 896. 
Miller, C. T., \& Kaiser, C. R. (2001). A theoretical perspective on coping with stigma. Journal of social issues, 57(1), 73-92.

Murphy, M. C., Richeson, J. A., Shelton, J. N., Rheinschmidt, M. L., \& Bergsieker, H. B. (2013). Cognitive costs of contemporary prejudice. Group Processes \& Intergroup Relations, 16(5), 560-571.

Phillips, L. T., \& Lowery, B. S. (2015). The hard-knock life? Whites claim hardships in response to racial inequity. Journal of Experimental Social Psychology, 61, 12-18.

Piff, P. K., Kraus, M. W., Côté, S., Cheng, B. H., \& Keltner, D. (2010). Having less, giving more: The influence of social class on prosocial behavior. Journal of Personality and Social Psychology, 99(5), 771-784.

Rand, D. G., Greene, J. D., \& Nowak, M. A. (2012). Spontaneous giving and calculated greed. Nature, 489(7416), 427-430.

Rattan, A., \& Ambady, N. (2013). Diversity ideologies and intergroup relations: An examination of colorblindness and multiculturalism. European Journal of Social Psychology, 43(1), $12-21$.

Richeson, J. A., \& Sommers, S. R. (2016). Toward a social psychology of race and race relations for the twenty-first century. Annual review of psychology, 67, 439-463.

Salvatore, J., \& Shelton, J. N. (2007). Cognitive costs of exposure to racial prejudice. Psychological science, 18(9), 810-815.

Society of Personality and Social Psychology. (2015). Membership report. Data retrieved from: http://ow.ly/d/4uk9

Sue, S. (1999). Science, ethnicity, and bias: Where have we gone wrong?. American Psychologist, 54(12), 1070-1077. 
Sue, D. W., Capodilupo, C. M., Torino, G. C., Bucceri, J. M., Holder, A., Nadal, K. L., \& Esquilin, M. (2007). Racial microaggressions in everyday life: Implications for clinical practice. American Psychologist, 62(4), 271-286.

Umberson, D., Olson, J. S., Crosnoe, R., Liu, H., Pudrovska, T., \& Donnelly, R. (2017). Death of family members as an overlooked source of racial disadvantage in the United States. Proceedings of the National Academy of Sciences, 201605599.

United States Supreme Court (1896). Plessy v. Ferguson. 163 US 537. Retrieved from: https://supreme.justia.com/cases/federal/us/163/537/case.html

Walton, G. M., \& Cohen, G. L. (2007). A question of belonging: Race, social fit, and achievement. Journal of Personality and Social Psychology, 92(1), 82-96.

Weber, M. (1930/2002). The Protestant ethic and the spirit of capitalism and other writings. Penguin. 
Microaggressions in Historical Context 21

\section{Acknowledgments}

We wish to acknowledge Alex Jones for providing inspiration and perspective during the preparation of this commentary. 